Check for updates

Cite this: Chem. Sci., 2018, 9, 3062

\title{
Observation of a new type of aggregation-induced emission in nanoclusters $\uparrow$
}

\begin{abstract}
Xi Kang, (D) Shuxin Wang (D) * and Manzhou Zhu (D) *
The strategy of aggregation-induced emission (AIE) has been widely used to enhance the photoluminescence $(\mathrm{PL})$ in the nanocluster $(\mathrm{NC})$ research field. Most of the previous reports on aggregationinduced enhancement of fluorescence in NCs are induced by the restriction of intramolecular motion (RIM). In this work, a novel mechanism involving the restriction of the "dissociation-aggregation pattern" of ligands is presented using a $\mathrm{Ag}_{29}(\mathrm{BDT})_{12}(\mathrm{TPP})_{4} \mathrm{NC}$ (BDT: 1,3-benzenedithiol; TPP: triphenylphosphine) as a model. By the addition of TPP into an $\mathrm{N}, \mathrm{N}$-dimethylformamide solution of $\mathrm{Ag}_{29}(\mathrm{BDT})_{12}(\mathrm{TPP})_{4}$, the PL intensity of the $\mathrm{Ag}_{29}(\mathrm{BDT})_{12}(\mathrm{TPP})_{4} \mathrm{NC}$ could be significantly enhanced (13 times, quantum yield from $0.9 \%$ to $11.7 \%$ ) due to the restricted TPP dissociation-aggregation process. This novel mechanism is further validated by a low-temperature PL study. Different from the significant PL enhancement of the $\mathrm{Ag}_{29}(\mathrm{BDT})_{12}(\mathrm{TPP})_{4} \mathrm{NC}$, the non-dissociative $\mathrm{Pt}_{1} \mathrm{Ag}_{28}(\mathrm{~S}-\mathrm{Adm})_{18}(\mathrm{TPP})_{4} \mathrm{NC}$ (S-Adm: 1-adamantanethiol) exhibits a maintained PL intensity under the same TPP-addition conditions. Overall, this work presents a new mechanism for largely enhancing the PL of NCs via modulating the dissociation of ligands on the NC surface, which is totally different from the previously reported AIE phenomena in the NC field.
\end{abstract}

Received 15th December 2017 Accepted 18th February 2018

DOI: $10.1039 / \mathrm{c} 7 \mathrm{sc} 05317 \mathrm{~g}$

rsc.li/chemical-science
AIE strategy is being expanded to the hydrocarbon, metal complex, metal NC, and macromolecular research fields. ${ }^{\mathbf{4 1}}$ The corresponding AIEgens have been widely applied in biological probing, chemical sensing, and organic light-emitting diodes, to name a few. ${ }^{42}$ In the NC field, the AIE strategy could boost the PL QY through facile approaches (e.g., solvent- or cationinducing approaches). ${ }^{19,25}$ Furthermore, the previously reported enhancements of fluorescence in NCs have mostly been achieved by the restriction of intramolecular motion (RIM, a general mechanism in AIE materials). ${ }^{19,25}$ This raises some interesting questions: are there any other patterns (other than RIM) of AIE that exist in the NC field? If so, how can we enhance the QY of fluorescent NCs with new patterns? Addressing these issues will not only develop a powerful and practical strategy for synthesizing more fluorescent NCs with enhanced PL QYs, but also promote wide-range application of AIE in the NC field.

Herein, a novel AIE pattern (the restriction of the ligand dissociation-aggregation process) is discovered using a $\mathrm{Ag}_{29}(\mathrm{BDT})_{12}(\mathrm{TPP})_{4} \mathrm{NC}$ (BDT, 1,3-benzenedithiol; TPP, triphenylphosphine) as a model. The PL intensity of the $\mathrm{Ag}_{29}(\mathrm{BDT})_{12}(\mathrm{TPP})_{4} \mathrm{NC}$ in the solid or crystal state is significantly higher than that in the solution state. Considering the particularly close packing of $\mathrm{Ag}_{29}(\mathrm{BDT})_{12}(\mathrm{TPP})_{4}$ as well as the existence of $\pi \cdots \pi$ and $\mathrm{C}-\mathrm{H} \cdots \pi$ interactions between the ligands, the AIE process is unlikely caused by the RIM completely in the case of the $\mathrm{Ag}_{29}(\mathrm{BDT})_{12}(\mathrm{TPP})_{4}$ NC. Furthermore, electrospray ionization mass spectrometry (ESI-MS) and ${ }^{31} \mathrm{P}$ nuclear magnetic resonance $\left({ }^{31} \mathrm{P} \mathrm{NMR}\right)$ analyses are performed on the $\mathrm{Ag}_{29}(\mathrm{BDT})_{12}(\mathrm{TPP})_{4} \mathrm{NC}$, and they reveal several dissociated 


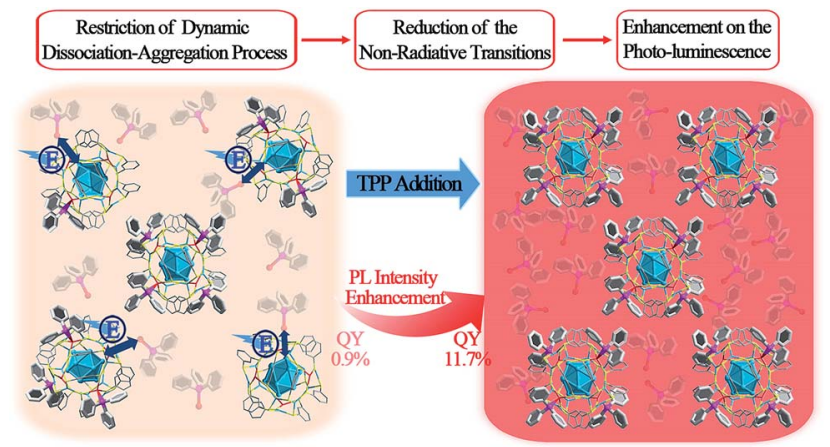

Scheme 1 Enhancement of PL intensity induced by the restriction of the TPP dissociation-aggregation process based on the $\mathrm{Ag}_{29}(\mathrm{BDT})_{12}(\mathrm{TPP})_{4} \mathrm{NC}$ in the solution state.

ligands from $\mathrm{Ag}_{29}(\mathrm{BDT})_{12}(\mathrm{TPP})_{4}$; that is, the mechanism of AIE in $\mathrm{Ag}_{29}(\mathrm{BDT})_{12}$ (TPP $)_{4}$ could be the restriction of the TPP dissociation-aggregation process. To prove the mechanism, different concentrations of TPP molecules are added to the dissociative $\mathrm{Ag}_{29}(\mathrm{BDT})_{12}(\mathrm{TPP})_{4}$ and non-dissociative $\mathrm{Pt}_{1} \mathrm{Ag}_{28}(\mathrm{~S}-\mathrm{Adm})_{18}(\mathrm{TPP})_{4}$ (S-Adm, 1-adamantanethiol) NC solution. Resultantly, the PL intensity of $\mathrm{Ag}_{29}(\mathrm{BDT})_{12}(\mathrm{TPP})_{4}$ is significantly enhanced (up to 13 times, with a PL QY from $0.9 \%$ to $11.7 \%$ ) by the addition of TPP owing to the restriction of the TPP dissociation-aggregation process (or the chemical equilibrium shifting to TPP aggregation on the $\mathrm{Ag}_{29}(\mathrm{BDT})_{12}(\mathrm{TPP})_{x} \mathrm{NCs}$, summarized in Scheme 1). By contrast, the non-dissociative $\mathrm{Pt}_{1} \mathrm{Ag}_{28}$ $(\mathrm{S}-\mathrm{Adm})_{18}(\mathrm{TPP})_{4}$ shows nearly the same intensity of PL after the addition of TPP. In addition, the temperature-dependent PL of the $\mathrm{Ag}_{29}(\mathrm{BDT})_{12}(\mathrm{TPP})_{4} \mathrm{NC}$ shows two segments of rising curves, which represent both the restriction of the TPP dissociation-aggregation process (the QY varies from $0.9 \%$ to $22.5 \%$ ) and the quenched thermal vibration process (the QY varies from $22.5 \%$ to about $100 \%$ ). However, the nondissociative $\mathrm{Pt}_{1} \mathrm{Ag}_{28}(\mathrm{~S}-\mathrm{Adm})_{18}(\mathrm{TPP})_{4}$ only exhibits a quenched thermal vibration process (the QY varies from 9.3\% to $\sim 100 \%)$.

\section{Experimental methods}

\section{Materials}

All chemicals including silver nitrate $\left(\mathrm{AgNO}_{3}, 99 \%\right.$, metal basis), hexachloroplatinic(Iv) acid $\left(\mathrm{H}_{2} \mathrm{PtCl}_{6} \cdot 6 \mathrm{H}_{2} \mathrm{O}, 99.99 \%\right.$, metals basis), triphenylphosphine (TPP, 99\%), benzene-1,3-dithiol (BDT, 99\%), 2,4-dimethylbenzenethiol ( $\mathrm{HSPhMe}_{2}, 99 \%$ ), 1-adamantanethiol $\left(\mathrm{HSC}_{10} \mathrm{H}_{15}, 99 \%\right)$, sodium borohydride $\left(\mathrm{NaBH}_{4}\right.$, 99.9\%), methylene chloride $\left(\mathrm{CH}_{2} \mathrm{Cl}_{2}\right.$, HPLC grade, Aldrich), acetic ether $\left(\mathrm{CH}_{3} \mathrm{COOC}_{2} \mathrm{H}_{5}\right.$, HPLC, Aldrich), methanol $\left(\mathrm{CH}_{3} \mathrm{OH}\right.$, HPLC, Aldrich), ethanol $\left(\mathrm{CH}_{3} \mathrm{CH}_{2} \mathrm{OH}, \mathrm{HPLC}\right.$, Aldrich) and $\mathrm{N}, \mathrm{N}$ dimethylformamide (DMF, HPLC, Aldrich) were purchased from Sigma-Aldrich and used without further purification. Pure water was purchased from Wahaha Co. Ltd. All glassware was thoroughly cleaned with aqua regia $\left(\mathrm{HCl}: \mathrm{HNO}_{3}=3: 1 \mathrm{v} / \mathrm{v}\right)$, rinsed with copious amounts of pure water, and then dried in an oven prior to use.

\section{Synthesis of the $\mathrm{Ag}_{29}(\mathrm{BDT})_{12}(\mathrm{TPP})_{4} \mathrm{NC}$}

The synthesis of the $\mathrm{Ag}_{29}(\mathrm{BDT})_{12}(\mathrm{TPP})_{4} \mathrm{NC}$ was performed following a method reported by Bakr and coworkers. ${ }^{27}$

\section{Synthesis of the $\mathrm{Pt}_{1} \mathrm{Ag}_{28}(\mathrm{~S}-\mathrm{Adm})_{18}(\mathrm{TPP})_{4} \mathbf{N C}$}

The synthesis of the $\mathrm{Pt}_{1} \mathrm{Ag}_{28}(\mathrm{~S}-\mathrm{Adm})_{18}(\mathrm{TPP})_{4} \mathrm{NC}$ was performed according to our previous work. ${ }^{43}$

\section{Synthesis of the $\mathrm{Pt}_{1} \mathrm{Ag}_{28}(\mathrm{BDT})_{12}(\mathrm{TPP})_{\mathbf{4}} \mathrm{NC}$}

The synthesis of the $\mathrm{Pt}_{1} \mathrm{Ag}_{28}(\mathrm{BDT})_{12}(\mathrm{TPP})_{4} \mathrm{NC}$ was performed following a method previously reported by Bakr and coworkers. $^{44}$

\section{Test of the TPP ligand concentration-PL intensity correlation}

$10 \mathrm{mg}$ of $\mathrm{Ag}_{29}(\mathrm{BDT})_{12}(\mathrm{TPP})_{4}$ (or $\mathrm{Pt}_{1} \mathrm{Ag}_{28}(\mathrm{~S}-\mathrm{Adm})_{18}(\mathrm{TPP})_{4}$ or $\left.\mathrm{Pt}_{1} \mathrm{Ag}_{28}(\mathrm{BDT})_{12}(\mathrm{TPP})_{4}\right) \mathrm{NC}$ was dissolved in $10 \mathrm{~mL}$ of DMF. Then the TPP ligand was added to the DMF solution with the molar ratio of TPP/NC ranging from 0.1 to 10 . The PL spectra were then measured for these mixed solutions.

\section{Test of the temperature-PL intensity correlation}

$10 \mathrm{mg}$ of $\mathrm{Ag}_{29}(\mathrm{BDT})_{12}(\mathrm{TPP})_{4}\left(\right.$ or Pt $\left._{1} \mathrm{Ag}_{28}(\mathrm{~S}-\mathrm{Adm})_{18}(\mathrm{TPP})_{4}\right) \mathrm{NC}$ was dissolved in $10 \mathrm{~mL}$ of DMF. Then the solutions were cooled to different temperatures and the PL spectra were measured.

\section{Characterization}

All UV-vis absorption spectra of NCs dissolved in DMF were recorded using an Agilent 8453 diode array spectrometer, with the background corrected by using a DMF blank. Solid samples were dissolved in DMF to make a dilute solution, which was transferred to a $1 \mathrm{~cm}$ path length quartz cuvette for spectral measurements.

PL spectra were measured on an FL-4500 spectrofluorometer with the same optical density (OD) of $\sim 0.05$. In these experiments, the NC solutions were prepared in DMF at a concentration of less than $1 \mathrm{mg} \mathrm{mL} \mathrm{m}^{-1}$.

Absolute quantum yields (QYs) were measured with dilute solutions of NCs ( 0.05 OD absorption at $445 \mathrm{~nm}$ ) on a HORIBA FluoroMax-4P.

${ }^{31} \mathrm{P}$ NMR spectra were acquired using a Bruker 600 Avance III spectrometer equipped with a Bruker BBO multinuclear probe (BrukerBioSpin, Rheinstetten, Germany). To achieve a sufficient signal-to-noise ratio, the ${ }^{31} \mathrm{P}$ NMR spectra were recorded by collecting $1 \mathrm{k}$ scans with a recycle delay time of $5 \mathrm{~s}$.

Electrospray ionization time-of-flight mass spectrometry (ESI-TOF-MS) measurements were performed on a MicrOTOFQIII high-resolution mass spectrometer.

\section{Results and discussion}

The $\mathrm{Ag}_{29}(\mathrm{BDT})_{12}(\mathrm{TPP})_{4} \mathrm{NC}$ was prepared following a method previously published by Bakr and coworkers. ${ }^{27}$ They also reported the crystal structure of $\mathrm{Ag}_{29}(\mathrm{BDT})_{12}(\mathrm{TPP})_{4} \cdot{ }^{27}$ The structure is shown in Fig. 1A and B. Regarding the structural anatomy, $\mathrm{Ag}_{29}(\mathrm{BDT})_{12}(\mathrm{TPP})_{4}$ is composed of a three-layer 
A)

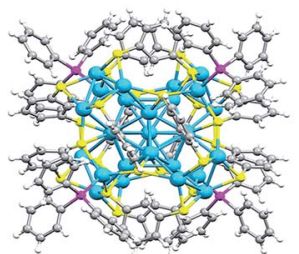

C)

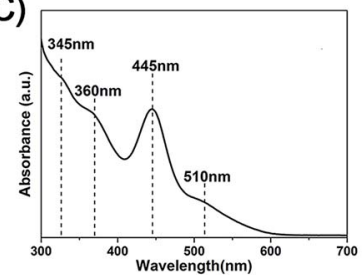

E)
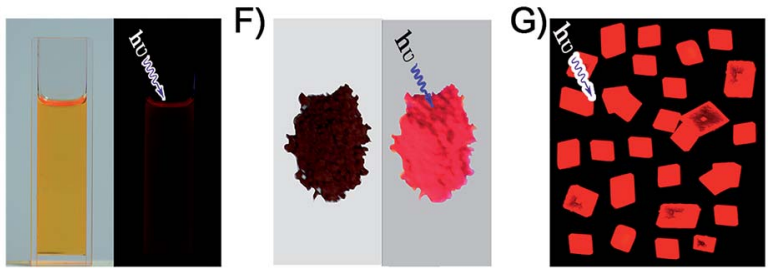

Fig. 1 (A) Total structure of the $\mathrm{Ag}_{29}(\mathrm{BDT})_{12}(\mathrm{TPP})_{4} \mathrm{NC}$ (redrawn from ref. 27). (B) Structural anatomy of the $\mathrm{Ag}_{29}(\mathrm{BDT})_{12}(\mathrm{TPP})_{4} \mathrm{NC}$. (C) UV-vis spectrum of the $\mathrm{Ag}_{29}(\mathrm{BDT})_{12}(\mathrm{TPP})_{4} \mathrm{NC}$ (dissolved in DMF). (D) $\mathrm{PL}$ excitation spectrum (black) and emission spectra (other colors) of the $\mathrm{Ag}_{29}(\mathrm{BDT})_{12}(\mathrm{TPP})_{4} \mathrm{NC}$. Digital photographs of the $\mathrm{Ag}_{29}(\mathrm{BDT})_{12}(\mathrm{TPP})_{4}$ $\mathrm{NC}$ in (E) solution state, (F) solid state, and (G) crystal state under visible or UV light. Color codes: cerulean/red spheres, Ag; yellow spheres, S; purple spheres, $\mathrm{P}$; grey spheres, $\mathrm{C}$; white spheres, $\mathrm{H}$.

configuration: the icosahedral $\mathrm{Ag}_{13}$ kernel is enclosed by four $\mathrm{Ag}_{3} \mathrm{~S}_{6}$ motifs to form a $\mathrm{Ag}_{25}(\mathrm{BDT})_{12}$ architecture (it should be noted that the four $\mathrm{Ag}_{3} \mathrm{~S}_{6}$ motifs are united by the BDT ligands); the $\mathrm{Ag}_{25}(\mathrm{BDT})_{12}$ architecture is further capped by four $\mathrm{Ag}-\mathrm{TPP}$ units. Fig. 1C shows the UV-vis spectrum of $\mathrm{Ag}_{29}(\mathrm{BDT})_{12}(\mathrm{TPP})_{4}$, which exhibits broad, multiband optical absorption bands centred at 345, 360, 445, and $510 \mathrm{~nm}$. Furthermore, $\mathrm{Ag}_{29}(\mathrm{BDT})_{12}(\mathrm{TPP})_{4}$ possesses an emission band centred at $642 \mathrm{~nm}$ (Fig. 1D). Additionally, the PL excitation spectrum is almost the same as the absorption spectrum (Fig. 1C and D), which is reminiscent of some previously reported fluorescent NCs as well as the quantum-dot behavior. ${ }^{22,25,45}$

It is noteworthy that the PL QY of $\mathrm{Ag}_{29}(\mathrm{BDT})_{12}(\mathrm{TPP})_{4}$ is only $0.9 \%$, which is too weak to be perceived by the naked eye (Fig. 1E). ${ }^{27,28}$ Interestingly, the $\mathrm{Ag}_{29}(\mathrm{BDT})_{12}(\mathrm{TPP})_{4} \mathrm{NC}$ exhibits enhanced fluorescence in the solid or crystal state (Fig. 1F and G). These observations suggest that the aggregation process significantly boosts the emission of $\mathrm{Ag}_{29}(\mathrm{BDT})_{12}(\mathrm{TPP})_{4}$. Previously, the RIM pattern was believed to be the primary cause either in the solvent- or ion-induced AIE process. ${ }^{19,25}$ In our current work, the AIE observed during the drying or crystallization process is obviously not relevant to any ionic effect, because our process only involves a solvent evaporation process.

The crystal structure of the $\mathrm{Ag}_{29}(\mathrm{BDT})_{12}(\mathrm{TPP})_{4} \mathrm{NC}$ is analyzed in order to gain insight into the aforementioned solvent evaporation-induced AIE. In the solution state, the energy dissipation of photo-excited $\mathrm{Ag}_{29}(\mathrm{BDT})_{12}(\mathrm{TPP})_{4}$ includes two pathways: (i) non-radiative transitions (mainly affected by intramolecular vibrations), and (ii) radiative transitions (through luminescence). Fig. 2A shows an illustration of intra-molecular vibrations of the $\mathrm{Ag}_{29}(\mathrm{BDT})_{12}(\mathrm{TPP})_{4} \mathrm{NC}$, which comprise rotavibrations and swing-vibrations. However, the considerable close-packing of the structural configuration (see the space-fill pattern in Fig. 2B) suggests that such vibrations are difficult. Furthermore, as mentioned above, each $\mathrm{Ag}_{3} \mathrm{~S}_{6}$ motif is linked by the BDT ligand, which restricts the vibrations of $\mathrm{Ag}-\mathrm{S}-\mathrm{Ag}$ motifs. Moreover, many $\pi \cdots \pi$ and $\mathrm{C}-\mathrm{H} \cdots \pi$ interactions among BDT or TPP ligands are observed. Specifically, every two neighboring benzene rings of BDT ligands interact through $\pi \cdots$ $\pi$ interaction, which forms 6 pairs of $\pi \cdots \pi$ interactions in total (Fig. 2C). In addition, the vibration of each of the ortho-position $\mathrm{C}-\mathrm{H}$ on TPP is rendered difficult owing to the $\mathrm{C}-\mathrm{H} \cdots \pi$ interaction with the nearby benzene ring of BDT (altogether 12 pairs of $\mathrm{C}-\mathrm{H} \cdots \pi$ interactions, shown in Fig. $2 \mathrm{C}$ ). To summarize, the main cause of the weak PL of the $\mathrm{Ag}_{29}(\mathrm{BDT})_{12}(\mathrm{TPP})_{4} \mathrm{NC}$ in solution is not thermal vibration, because the architecture of the $\mathrm{Ag}_{29}(\mathrm{BDT})_{12}(\mathrm{TPP})_{4} \mathrm{NC}$ exhibits strong rigidity. Consequently, the AIE of the $\mathrm{Ag}_{29}(\mathrm{BDT})_{12}(\mathrm{TPP})_{4} \mathrm{NC}$ is unlikely induced by the RIM pattern completely.

The above discussion raises an interesting question: what is the essential role of the AIE in the $\mathrm{Ag}_{29}(\mathrm{BDT})_{12}(\mathrm{TPP})_{4} \mathrm{NC}$ ? From the ESI-MS spectrum of $\mathrm{Ag}_{29}(\mathrm{BDT})_{12}(\mathrm{TPP})_{4}$ (Fig. 3A, see Fig. S1† for the expansion of the spectrum, and Fig. S2 $\uparrow$ for the comparison of the experimental and simulated isotope patterns), we find that the TPP ligands are capable of dissociation to generate $\mathrm{Ag}_{29}(\mathrm{BDT})_{12}(\mathrm{TPP})_{x}(x=0-3)$ and the dissociated TPP ligands. For instance, the highest signal in the ESI-MS spectrum is the peak of $\mathrm{Ag}_{29}(\mathrm{BDT})_{12}(\mathrm{TPP})_{2}$, which is generated
A)



C) i)
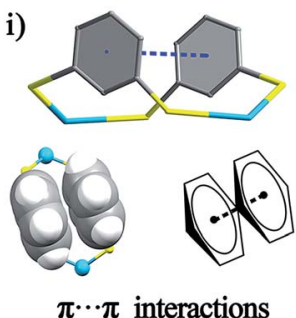

B)

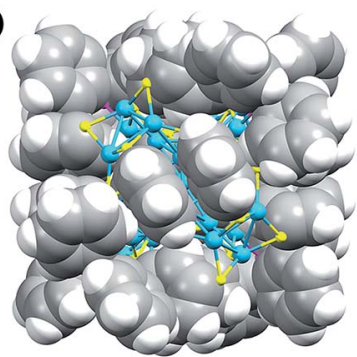

ii)
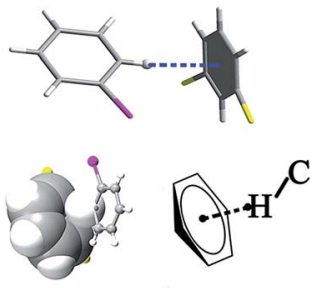

$\mathrm{C}-\mathrm{H} \cdots \pi$ interactions
Fig. 2 (A) Illustration of the vibration patterns in the $\mathrm{Ag}_{29}(\mathrm{BDT})_{12}(\mathrm{TPP})_{4}$ NC. (B) The space-fill pattern of the crystal structure of the $\mathrm{Ag}_{29}(\mathrm{BDT})_{12}(\mathrm{TPP})_{4} \mathrm{NC}$. (C) (i) The $\pi \cdots \pi$ interaction between neighboring benzene rings on BDT ligands, and (ii) the $\mathrm{C}-\mathrm{H} \cdots \pi$ interaction between ortho-position $\mathrm{C}-\mathrm{H}$ on TPP and benzene rings on BDT ligands. Color codes: cerulean spheres, Ag; yellow spheres, S; purple spheres, $\mathrm{P}$; grey spheres, $\mathrm{C}$; white spheres, $\mathrm{H}$. 


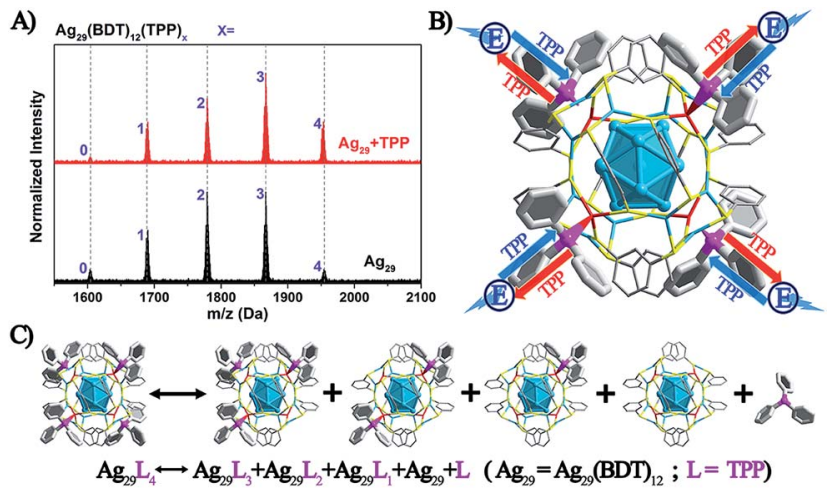

Fig. 3 (A) ESI-MS spectra of the $\mathrm{Ag}_{29}(\mathrm{BDT})_{12}(\mathrm{TPP})_{4} \mathrm{NC}$ with or without the addition of TPP. (B) Illustration of the dynamic TPP dissociationaggregation process on the $\mathrm{Ag}_{29}(\mathrm{BDT})_{12}(\mathrm{TPP})_{4}$ and the corresponding energy loss. (C) The dynamic TPP dissociation-aggregation reversible reaction. Color codes: cerulean/red spheres, Ag; yellow spheres, S; purple spheres, $\mathrm{P}$; grey spheres, $\mathrm{C}$; white spheres, $\mathrm{H}$.

by dissociating two TPP ligands of the intact NC. To further validate the TPP dissociation process of $\mathrm{Ag}_{29}(\mathrm{BDT})_{12}(\mathrm{TPP})_{4}$ in the solution state, ESI-MS measurements were also performed on the mixture of $\mathrm{Ag}_{29}(\mathrm{BDT})_{12}(\mathrm{TPP})_{4} \mathrm{NC}$ with extra TPP. The spectrum (Fig. 3A, red line) exhibits a stronger signal of the intact $\mathrm{Ag}_{29}(\mathrm{BDT})_{12}(\mathrm{TPP})_{4} \mathrm{NC}$ compared with the case of the $\mathrm{Ag}_{29}(\mathrm{BDT})_{12}(\mathrm{TPP})_{4} \mathrm{NC}$ only (Fig. 3A, black line), which indicates a suppressed dissociation process with extra TPP in solution (note that because of the dilution process in the ESI-MS measurements, there were still lots of dissociated $\mathrm{Ag}_{29}(\mathrm{BDT})_{12}(\mathrm{TPP})_{x}$ signals in the sample mixture). Therefore, based on the ESI-MS results, the reversible reaction of the $\mathrm{Ag}_{29}(\mathrm{BDT})_{12}(\mathrm{TPP})_{4} \mathrm{NC}$ in solution could be determined to be $\mathrm{Ag}_{29}(\mathrm{BDT})_{12}(\mathrm{TPP})_{4} \leftrightarrow \mathrm{Ag}_{29}(\mathrm{BDT})_{12}(\mathrm{TPP})_{3}+$ $\mathrm{Ag}_{29}(\mathrm{BDT})_{12}(\mathrm{TPP})_{2}+\mathrm{Ag}_{29}(\mathrm{BDT})_{12}(\mathrm{TPP})_{1}+\mathrm{Ag}_{29}(\mathrm{BDT})_{12}+\mathrm{TPP}($ shown in Fig. 3C). Accordingly, the TPP ligands on the $\mathrm{Ag}_{29}(\mathrm{BDT})_{12}(\mathrm{TPP})_{4}$ $\mathrm{NC}$ are in dynamic dissociation/aggregation. It is suggested that the breaking of coordination bonds would consume energy, ${ }^{46}$ and thus the energy loss with non-radiative transitions would influence the energy release with the radiative transition. Specifically, the TPP dissociation process would consume vast amounts of energy, which could be used to explain the result of low PL of the photo-excited $\mathrm{Ag}_{29}(\mathrm{BDT})_{12}(\mathrm{TPP})_{4} \mathrm{NC}$ in the solution state. Thus, we speculate that the significantly enhanced PL of the $\mathrm{Ag}_{29}(\mathrm{BDT})_{12}(\mathrm{TPP})_{4} \mathrm{NC}$ in the solid or crystal state should arise from the restriction of the TPP dissociation-aggregation process - which inhibits the non-radiative pathways, and thus enhances the radiative pathway (PL). Therefore, the AIE of the $\mathrm{Ag}_{29}(\mathrm{BDT})_{12}(\mathrm{TPP})_{4} \mathrm{NC}$ could be induced by the restriction of the ligand dissociation-aggregation process.

Considering that the TPP dissociation-aggregation process is a reversible reaction, we are motivated to control the reversible process to control the intensity of PL. As shown in Fig. 4, an increasing proportion (molar ratio) of TPP added to the DMF solution of $\mathrm{Ag}_{29}(\mathrm{BDT})_{12}(\mathrm{TPP})_{4}$ increases the PL intensity rapidly in the beginning, and then it levels off, with the highest PL QY being $11.7 \%$, which is in striking contrast to the weakly luminescent $\mathrm{Ag}_{29}(\mathrm{BDT})_{12}(\mathrm{TPP})_{4}$ NC with no TPP addition

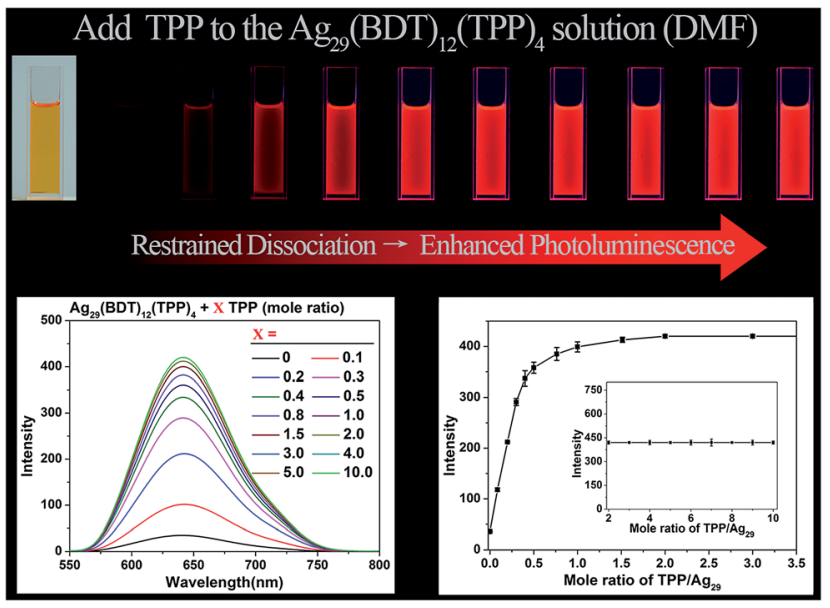

Fig. $4 \mathrm{PL}$ variation trend of the $\mathrm{Ag}_{29}(\mathrm{BDT})_{12}(\mathrm{TPP})_{4} \mathrm{NC}$ resulting from the addition of different molar ratios of TPP ligand. (Top) PL intensity variation monitored by digital photography of the $\mathrm{Ag}_{29}(\mathrm{BDT})_{12}(\mathrm{TPP})_{4}$ $\mathrm{NC}$ in the solution state under UV light. (Bottom-left) PL intensity variation monitored using the fluorescence spectrometer. (Bottomright) $\mathrm{PL}$ intensity variation monitored at the fixed point of $642 \mathrm{~nm}$.

$(\mathrm{QY}=0.9 \%$ ). A quantitative test was performed to obtain the relationship between the PL intensity and the amount of TPP added (Fig. 4, bottom-left). When adding a 0.1 molar ratio of TPP (versus NC) to the DMF solution of $\mathrm{Ag}_{29}(\mathrm{BDT})_{12}(\mathrm{TPP})_{4} \mathrm{NC}$, the PL intensity increases by almost 3 times compared with the initial state. Furthermore, by the further addition of TPP, the QY enhancement gradually becomes steady. Finally, a 13-fold enhancement compared to the initial state is achieved when the amount of added TPP is greater than 2 (molar ratio). The PL intensity at $642 \mathrm{~nm}$ is compared (Fig. 4, bottom-right), which also confirms the PL variation trend in the PL QY test (i.e., the increasing trend as well as the 13-fold enhancement). To sum up, the redundant TPP ligands will prevent the TPP dissociation-aggregation process on the nanocluster surface, and then enhance the PL intensity of the $\mathrm{Ag}_{29}(\mathrm{BDT})_{12}(\mathrm{TPP})_{4} \mathrm{NC}$.

For comparison, the same TPP-addition experiment was performed on the $\mathrm{Pt}_{1} \mathrm{Ag}_{28}(\mathrm{~S}-\mathrm{Adm})_{18}(\mathrm{TPP})_{4} \mathrm{NC}$ (see Fig. S3† for the structural anatomy of $\left.\mathrm{Pt}_{1} \mathrm{Ag}_{28}(\mathrm{~S}-\mathrm{Adm})_{18}(\mathrm{TPP})_{4}\right){ }^{43}$ The ESI-MS of the $\mathrm{Pt}_{1} \mathrm{Ag}_{28}(\mathrm{~S}-\mathrm{Adm})_{18}(\mathrm{TPP})_{4}$ NC shows a distinct peak at 3637.63 Da (Fig. 5, bottom-left), which clearly illustrates the non-dissociated state of TPP ligands of this NC in the DMF solution. The unchanged ESI-MS and UV-vis spectra after the addition of TPP ligands illustrate that the as-synthesized nanoclusters will not decompose or transform in this operation (Fig. S4 $\dagger$ ). Importantly, in sharp contrast to the PL variation trend of the $\mathrm{Ag}_{29}(\mathrm{BDT})_{12}(\mathrm{TPP})_{4} \mathrm{NC}$, the PL intensity of the $\mathrm{Pt}_{1} \mathrm{Ag}_{28}(\mathrm{~S}-\mathrm{Adm})_{18}(\mathrm{TPP})_{4} \mathrm{NC}$ maintains a $\mathrm{QY}$ of $9.3 \%$ no matter how high the TPP amount added to the solution is (Fig. 5, top). Note that the PL QY of $\mathrm{Pt}_{1} \mathrm{Ag}_{28}(\mathrm{~S}-\mathrm{Adm})_{18}(\mathrm{TPP})_{4}$ in $\mathrm{CH}_{2} \mathrm{Cl}_{2}$ is $4.9 \%,{ }^{43}$ which illustrates the solvent effect on the PL of $\mathrm{Pt}_{1} \mathrm{Ag}_{28}(\mathrm{~S}-\mathrm{Adm})_{18}(\mathrm{TPP})_{4}$. The $\mathrm{PL}$ intensity of the $\mathrm{Pt}_{1} \mathrm{Ag}_{28}(\mathrm{~S}-\mathrm{Adm})_{18}(\mathrm{TPP})_{4} \mathrm{NC}$ monitored at $672 \mathrm{~nm}$ by fluorescence spectroscopy also indicates the unchanged fluorescence (Fig. 5, bottom-right). In other words, the non-dissociative 


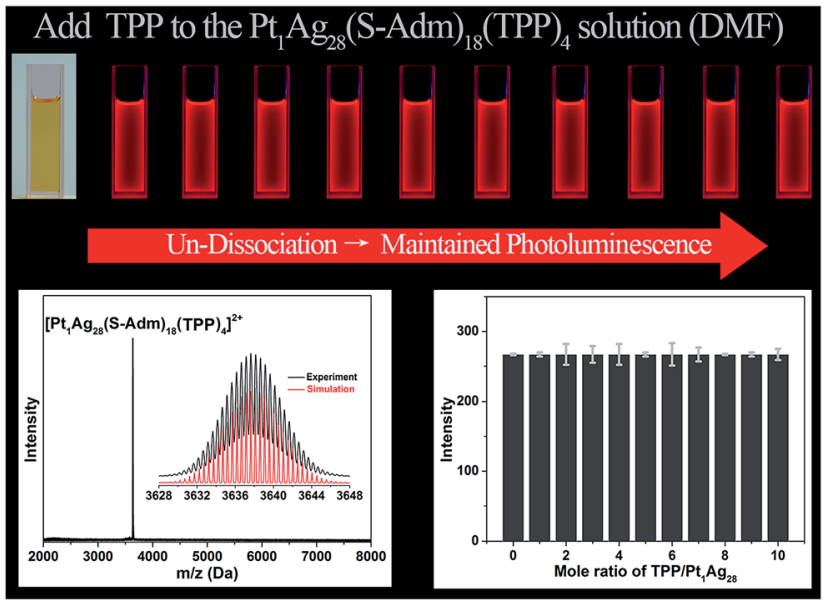

Fig. $5 \mathrm{PL}$ variation trend of the $\mathrm{Pt}_{1} \mathrm{Ag}_{28}(\mathrm{~S}-\mathrm{Adm})_{18}(\mathrm{TPP})_{4} \mathrm{NC}$ resulting from the addition of different molar ratios of TPP. (Top) PL intensity variation monitored using the digital photographs of the $\mathrm{Pt}_{1} \mathrm{Ag}_{28}(\mathrm{~S}-\mathrm{Adm})_{18}(\mathrm{TPP})_{4} \mathrm{NC}$ in the solution state under UV light (Bottom-left) ESI-MS spectrum of the $\mathrm{Pt}_{1} \mathrm{Ag}_{28}(\mathrm{~S}-\mathrm{Adm})_{18}(\mathrm{TPP})_{4} \mathrm{NC}$. Insets: experimental and simulated isotope patterns. (Bottom-right) PL intensity variation monitored at the fixed point of $672 \mathrm{~nm}$.

$\mathrm{Pt}_{1} \mathrm{Ag}_{28}(\mathrm{~S}-\mathrm{Adm})_{18}(\mathrm{TPP})_{4} \mathrm{NC}$ does not display any equilibrium dissociation-aggregation process, and thus the addition of TPP would not alter the PL intensity in the solution state. The sharp contrast between the $\mathrm{PL}$ variation trends of the $\mathrm{Ag}_{29}(\mathrm{BDT})_{12}(\mathrm{TPP})_{4}$ and $\mathrm{Pt}_{1} \mathrm{Ag}_{28}(\mathrm{~S}-\mathrm{Adm})_{18}(\mathrm{TPP})_{4}$ NCs indicates that the restriction of the ligand dissociation-aggregation process should be the major underlying mechanism of AIE in the $\mathrm{Ag}_{29}(\mathrm{BDT})_{12}(\mathrm{TPP})_{4} \mathrm{NC}$.

Additionally, in order to structurally and compositionally match the $\mathrm{Pt}_{1} \mathrm{Ag}_{28}(\mathrm{~S}-\mathrm{Adm})_{18}(\mathrm{TPP})_{4} \mathrm{NC}$, the TPP-addition experiment was performed on a Pt centrally doped $\mathrm{Ag}_{29}(\mathrm{BDT})_{12}(\mathrm{TPP})_{4}$ $\mathrm{NC}$ (that is, $\left.\mathrm{Pt}_{1} \mathrm{Ag}_{28}(\mathrm{BDT})_{12}(\mathrm{TPP})_{4} \mathrm{NC}\right) .{ }^{44}$ As shown in Fig. S5, $\dagger$ the PL intensity of $\mathrm{Pt}_{1} \mathrm{Ag}_{28}(\mathrm{BDT})_{12}(\mathrm{TPP})_{4}$ also exhibits significant enhancement by the addition of TPP (the maximum PL QY was $18.9 \%$ ), which is similar to the case of $\mathrm{Ag}_{29}(\mathrm{BDT})_{12}(\mathrm{TPP})_{4}$; hence, Pt doping is not the critical factor for PL enhancement with TPP addition. Specifically, the fluorescence intensity (centered at $720 \mathrm{~nm}$ ) rises rapidly during the initial TPP addition and then levels off once the molar ratio (TPP to $\left.\mathrm{Pt}_{1} \mathrm{Ag}_{28}(\mathrm{BDT})_{12}(\mathrm{TPP})_{4} \quad \mathrm{NC}\right)$ is greater than 1.5. A 7-fold enhancement is finally obtained by the addition of TPP to the $\mathrm{Pt}_{1} \mathrm{Ag}_{28}(\mathrm{BDT})_{12}(\mathrm{TPP})_{4}$ NC. Considering the same PL enhancement phenomenon of the $\mathrm{Pt}_{1} \mathrm{Ag}_{28}(\mathrm{BDT})_{12}(\mathrm{TPP})_{4}$ and $\mathrm{Ag}_{29}(\mathrm{BDT})_{12}(\mathrm{TPP})_{4}$ NCs with the addition of TPP ligands, the difference in the metallic composition is unlikely to be the primary cause for being dissociative or not of these NCs. The major different between the dissociative $\mathrm{Ag}_{29}(\mathrm{BDT})_{12}(\mathrm{TPP})_{4}$ and non-dissociative $\mathrm{Pt}_{1} \mathrm{Ag}_{28}(\mathrm{~S}-\mathrm{Adm})_{18}(\mathrm{TPP})_{4}$ nanoclusters is the outer ligands (BDT vs. S-Adm). The difference of these two ligands largely affects the structure of the metallic kernel and outer complex shell, which is a critical factor in the dissociative/ non-dissociative phenomenon (see Fig. S6† for the structural anatomies of the $\mathrm{Pt}_{1} \mathrm{Ag}_{28}(\mathrm{BDT})_{12}(\mathrm{TPP})_{4}$ as well as the $\left.\mathrm{Pt}_{1} \mathrm{Ag}_{28}(\mathrm{~S}-\mathrm{Adm})_{18}(\mathrm{TPP})_{4}\right)$.
${ }^{31} \mathrm{P}$ NMR was performed to validate the TPP dynamic dissociation-aggregation state of the $\mathrm{Ag}_{29}(\mathrm{BDT})_{12}(\mathrm{TPP})_{4}$ and $\mathrm{Pt}_{1} \mathrm{Ag}_{28}(\mathrm{~S}-\mathrm{Adm})_{18}(\mathrm{TPP})_{4}$ NCs. As shown in Fig. S7 and $\mathrm{S} 8, \uparrow$ the ${ }^{31} \mathrm{P}$ NMR spectrum of the $\mathrm{Ag}_{29}(\mathrm{BDT})_{12}(\mathrm{TPP})_{4} \mathrm{NC}$ (without the addition of TPP) exhibits a broad peak (half-peak width $\sim 0.85 \mathrm{ppm}$ ), which narrows down continuously with the addition of more TPP (the peak width finally reduces to $0.17 \mathrm{ppm}$ with a large excess of TPP in the $\mathrm{Ag}_{29}(\mathrm{BDT})_{12}(\mathrm{TPP})_{4}$ solution). The notable decrease in the peak width illustrates that the state of $\mathrm{P}$ is uniformalized; that is, the TPP dynamic dissociationaggregation extent of the $\mathrm{Ag}_{29}(\mathrm{BDT})_{12}(\mathrm{TPP})_{4} \mathrm{NC}$ in solution is remarkably suppressed with the addition of excess TPP. Furthermore, the maintained width of the ${ }^{31} \mathrm{P}$ NMR peak (half-peak width by $0.02 \mathrm{ppm}$, shown in Fig. S9†) for the $\mathrm{Pt}_{1} \mathrm{Ag}_{28}(\mathrm{~S}-\mathrm{Adm})_{18}(\mathrm{TPP})_{4}$ with or without TPP addition demonstrates the TPP non-dissociated state of the $\mathrm{Pt}_{1} \mathrm{Ag}_{28}(\mathrm{~S}-\mathrm{Adm})_{18}(\mathrm{TPP})_{4} \mathrm{NC}$.

It is well known that the temperature would significantly influence the dissociation-aggregation dynamic equilibrium process. Thus, to further verify the above-mentioned AIE mechanism, the temperature-PL intensity correlation of the $\mathrm{Ag}_{29}(\mathrm{BDT})_{12}(\mathrm{TPP})_{4}$ and $\mathrm{Pt}_{1} \mathrm{Ag}_{28}(\mathrm{~S}-\mathrm{Adm})_{18}(\mathrm{TPP})_{4}$ NCs was monitored. As shown in Fig. 6A and $\mathrm{B}$ and S10, $\dagger$ the temperaturedependent fluorescence of the $\mathrm{Ag}_{29}(\mathrm{BDT})_{12}(\mathrm{TPP})_{4} \mathrm{NC}$ shows two stages: (1) when the temperature is reduced from $293 \mathrm{~K}$ to $251 \mathrm{~K}$, the fluorescence shows a 25-fold enhancement (in this state the UV-vis absorption is maintained, and thus the PL QY increases from $0.9 \%$ to $22.5 \%$ ), and (2) the fluorescence intensity is increased significantly (a 280-fold boost comparing the $107 \mathrm{~K}$ data with the $293 \mathrm{~K}$ data) when the temperature is reduced to $107 \mathrm{~K}$, and the $\mathrm{UV}$-vis absorption presents a 2.5-fold enhancement (Fig. S11†). Accordingly, the PL QY increases almost to $100 \%$. The fluorescence of the $\mathrm{Ag}_{29}(\mathrm{BDT})_{12}(\mathrm{TPP})_{4} \mathrm{NC}$ appeared to be extremely bright at $107 \mathrm{~K}$, which is in striking contrast to the nearly invisible fluorescence at room
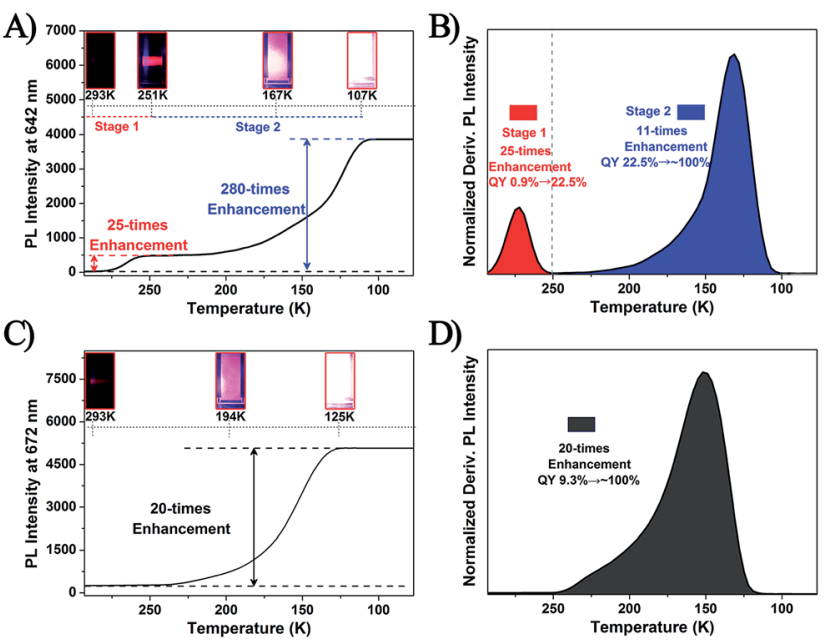

D)

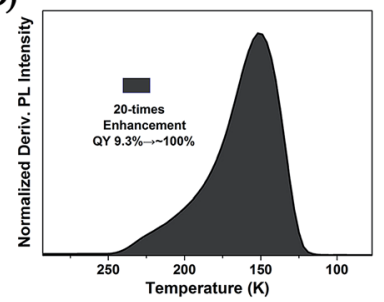

Fig. 6 The PL intensity at the fixed points of (A) $642 \mathrm{~nm}$ for the $\mathrm{Ag}_{29}(\mathrm{BDT})_{12}(\mathrm{TPP})_{4} \mathrm{NC}$ and (C) $672 \mathrm{~nm}$ for the $\mathrm{Pt}_{1} \mathrm{Ag}_{28}(\mathrm{~S}-\mathrm{Adm})_{18}(\mathrm{TPP})_{4}$ $\mathrm{NC}$ at different temperatures. Insets: the digital photographs of each $N C$ in DMF solution under UV light. The derivative results for $\mathrm{PL}$ intensity of (B) $\mathrm{Ag}_{29}(\mathrm{BDT})_{12}(\mathrm{TPP})_{4}$ and (D) $\mathrm{Pt}_{1} \mathrm{Ag}_{28}(\mathrm{~S}-\mathrm{Adm})_{18}(\mathrm{TPP})_{4} \mathrm{NCs}$. 
temperature (Fig. 6A, insets). In strong contrast, the nondissociative $\mathrm{Pt}_{1} \mathrm{Ag}_{28}(\mathrm{~S}-\mathrm{Adm})_{18}(\mathrm{TPP})_{4} \mathrm{NC}$ exhibits only one stage during the same temperature lowering process (Fig. 6C and D and S12 $\dagger$ ), and finally exhibits a 20 -fold enhancement of PL intensity and 1.9-fold enhancement of UV-vis absorption (Fig. S13†). Thus, the PL QY of the $\mathrm{Pt}_{1} \mathrm{Ag}_{28}(\mathrm{~S}-\mathrm{Adm})_{18}(\mathrm{TPP})_{4} \mathrm{NC}$ in the final stage is also nearly $100 \%$. Furthermore, it should be noted that the single stage of $\mathrm{Pt}_{1} \mathrm{Ag}_{28}(\mathrm{~S}-\mathrm{Adm})_{18}(\mathrm{TPP})_{4}$ is similar to stage 2 of the $\mathrm{Ag}_{29}(\mathrm{BDT})_{12}(\mathrm{TPP})_{4}$ NC. Therefore, the PL boost in stage 2 of the $\mathrm{Ag}_{29}(\mathrm{BDT})_{12}(\mathrm{TPP})_{4} \mathrm{NC}$ as well as in $\mathrm{Pt}_{1} \mathrm{Ag}_{28}(\mathrm{~S}-\mathrm{Adm})_{18}(\mathrm{TPP})_{4}$ should be completely induced by the suppression of thermal energy dissipation (or by the RIM pattern). Additionally, because the TPP dissociation process is much more sensitive to the temperature, the PL enhancement in stage 1 of the $\mathrm{Ag}_{29}(\mathrm{BDT})_{12}(\mathrm{TPP})_{4} \mathrm{NC}$ should be mainly caused by the restriction of the TPP dissociation-aggregation process. Because this restriction process is easily influenced by the temperature variation, stage 1 is observed in the relatively hightemperature region (compared with stage 2 in the lower temperature region). To sum up, decreasing the temperature (from r.t. to $251 \mathrm{~K}$ ) is effective in restricting the TPP dissociation-aggregation process which will lead to a significant enhancement in the fluorescence of the $\mathrm{Ag}_{29}(\mathrm{BDT})_{12}(\mathrm{TPP})_{4} \mathrm{NC}$ in the solution state.

It should be noted that the PL enhancement of the $\mathrm{Ag}_{29}(\mathrm{BDT})_{12}(\mathrm{TPP})_{4} \mathrm{NC}$ in the TPP addition process and temperature reduction process is different (13 times versus 25 times, with no increase in UV/vis absorption). In the TPP addition process, we find that the half-peak width (in the ${ }^{31} \mathrm{P}$ NMR spectrum) of the $\mathrm{Ag}_{29}(\mathrm{BDT})_{12}(\mathrm{TPP})_{4} \mathrm{NC}$ shows a continual decrease with the addition of TPP; however, the half-peak width in the final state is also wider than that in the $\mathrm{Pt}_{1} \mathrm{Ag}_{28}(\mathrm{~S}-\mathrm{Adm})_{18}(\mathrm{TPP})_{4} \quad \mathrm{NC} \quad(0.17$ versus $0.02 \mathrm{ppm})$. This suggests that the TPP dissociation-aggregation dynamic equilibrium in the $\mathrm{Ag}_{29}(\mathrm{BDT})_{12}(\mathrm{TPP})_{4} \mathrm{NC}$ is not completely prohibited, but is just limited to a certain extent. In other words, the non-radiative pathways caused by the TPP dissociationaggregation process still exist, even with the excess dose of TPP, which makes it difficult to reach the highest PL (with the non-dissociated state) of the $\mathrm{Ag}_{29}(\mathrm{BDT})_{12}(\mathrm{TPP})_{4}$ NC. By contrast, the non-dissociated state could be easily achieved in the temperature reduction process, and apparently, the $\mathrm{Ag}_{29}(\mathrm{BDT}){ }_{12}(\mathrm{TPP})_{4} \mathrm{NC}$ in the non-dissociated state (at $251 \mathrm{~K}$ ) exhibits a higher PL QY than the final state in the TPP addition process (22.5\% versus $11.7 \%)$.

\section{Conclusions}

In summary, a novel mechanism of aggregation-induced emission is discovered in nanoclusters, which involves the restriction of the ligand dissociation-aggregation process. The fluorescence intensity of $\mathrm{Ag}_{29}(\mathrm{BDT})_{12}$ (TPP $)_{4}$ can be significantly enhanced (about 13 -fold, quantum yield from $0.9 \%$ to $11.7 \%$ ) via promoting the aggregation of TPP onto the easy-todissociate nanocluster surface. Furthermore, the TPP dissociation-aggregation dynamic equilibrium process of $\mathrm{Ag}_{29}(\mathrm{BDT})_{12}(\mathrm{TPP})_{4}$ is also restrained by reducing the temperature, which results in enhanced photoluminescence intensity (25-fold) in $\mathrm{Ag}_{29}(\mathrm{BDT})_{12}(\mathrm{TPP})_{4}$. In contrast, the same experiments performed on the non-dissociative $\mathrm{Pt}_{1} \mathrm{Ag}_{28}(\mathrm{~S}-\mathrm{Adm})_{18}(\mathrm{TPP})_{4}$ nanocluster do not show any $\mathrm{PL}$ enhancement. These different results are not caused by the presence of the Pt dopant, but by the different thiolate ligands (BDT versus S-Adm). The retained PL intensity in the case of $\mathrm{Pt}_{1} \mathrm{Ag}_{28}(\mathrm{~S}-\mathrm{Adm})_{18}(\mathrm{TPP})_{4}$ validates the aforementioned mechanism for the $\mathrm{Ag}_{29}(\mathrm{BDT})_{12}(\mathrm{TPP})_{4}$ nanocluster. Overall, this work presents a new mechanism of aggregation-induced emission in nanoclusters. In addition to previous studies on the enhancement of nanocluster photo-luminescence, this work will hopefully draw greater attention of optical and theoretical chemists to fully understand the photo-luminescence properties of metal nanoclusters. Future work will focus on extending this new AIE mechanism to other fluorescent nanoclusters.

\section{Conflicts of interest}

There are no conflicts to declare.

\section{Acknowledgements}

We acknowledge the financial support by the NSFC (21372006, U1532141 \& 21631001), the Ministry of Education, the Education Department of Anhui Province, and the 211 Project of Anhui University.

\section{Notes and references}

1 R. Jin, C. Zeng, M. Zhou and Y. Chen, Chem. Rev., 2016, 116, 10346.

2 I. Chakraborty and T. Pradeep, Chem. Rev., 2017, 117, 8208.

3 P. Liu, R. Qin, G. Fu and N. Zheng, J. Am. Chem. Soc., 2017, 139, 2122.

4 Z. Hu and L. Jensen, Chem. Sci., 2017, 8, 4595.

5 X.-K. Wan, J.-Q. Wang, Z.-A. Nan and Q.-M. Wang, Sci. Adv., 2017, 3, e1701823.

6 D. M. Black, C. M. Crittenden, J. S. Brodbelt and R. L. Whetten, J. Phys. Chem. Lett., 2017, 8, 1283.

7 S. Yamazoe, K. Koyasu and T. Tsukuda, Acc. Chem. Res., 2014, 47, 816.

8 Z. Gan, Y. Lin, L. Luo, G. Han, W. Liu, Z. Liu, C. Yao, L. Weng, L. Liao, J. Chen, X. Liu, Y. Luo, C. Wang, S. Wei and Z. Wu, Angew. Chem., Int. Ed., 2016, 55, 11567.

9 Y. Niihori, S. Hossain, S. Sharma, B. Kumar, W. Kurashige and Y. Negishi, Chem. Rec., 2017, 17, 473.

10 X. Yuan, X. Dou, K. Zheng and J. Xie, Part. Part. Syst. Charact., 2015, 32, 613.

11 N. A. Sakthivel, S. Theivendran, V. Ganeshraj, A. G. Oliver and A. Dass, J. Am. Chem. Soc., 2017, 139, 15450.

12 G. Hu, Q. Tang, D. Lee, Z. Wu and D.-e. Jiang, Chem. Mater., 2017, 29, 4840.

13 Y. Wang, X.-K. Wan, L. Ren, H. Su, G. Li, S. Malola, S. Lin, Z. Tang, H. Häkkinen, B. K. Teo, Q.-M. Wang and N. Zheng, J. Am. Chem. Soc., 2016, 138, 3278. 
14 K. K. Chakrahari, J.-H. Liao, S. Kahlal, Y.-C. Liu, M.-H. Chiang, J.-Y. Saillard and C. W. Liu, Angew. Chem., Int. Ed., 2016, 55, 14704.

15 K. L. D. M. Weerawardene and C. M. Aikens, J. Am. Chem. Soc., 2016, 138, 11202.

16 I. Dolamic, S. Knoppe, A. Dass and T. Bürgi, Nat. Commun., 2012, 3, 798.

17 Z. Hu and L. Jensen, Chem. Sci., 2017, 8, 4595.

18 (a) Y. Yu, Z. Luo, D. M. Chevrier, D. T. Leong, P. Zhang, D.-e. Jiang and J. Xie, J. Am. Chem. Soc., 2014, 136, 1246; (b) S.-S. Zhang, L. Feng, R. D. Senanayake, C. M. Aikens, X.-P. Wang, Q.-Q. Zhao, C.-H. Tung and D. Sun, Chem. Sci., 2018, 9, 1251; (c) N. Goswami, Q. Yao, T. Chen and J. Xie, Coord. Chem. Rev., 2016, 329, 1; (d) X. Kang, L. Xiong, S. Wang, Y. Pei and M. Zhu, Chem. Commun., 2017, 53, 12564; (e) N. Goswami, Z. Luo, X. Yuan, D. T. Leong and J. Xie, Mater. Horiz., 2017, 4, 817; (f) M. S. Bootharaju, S. M. Kozlov, Z. Cao, M. Harb, N. Maity, A. Shkurenko, M. R. Parid, M. N. Hedhili, M. Eddaoudi, O. F. Mohammed, O. M. Bakr, L. Cavallo and J.-M. Basset, J. Am. Chem. Soc., 2017, 139, 1053; (g) K. Zheng, M. I. Setyawati, D. T. Leong and J. Xie, Coord. Chem. Rev., 2018, 357, 1.

19 (a) Z. Luo, X. Yuan, Y. Yu, Q. Zhang, D. T. Leong, J. Y. Lee and J. Xie, J. Am. Chem. Soc., 2012, 134, 16662; (b) N. Goswami, Q. Yao, Z. Luo, J. Li, T. Chen and J. Xie, J. Phys. Chem. Lett., 2016, 7, 962.

20 Z. Wu, H. Liu, T. Li, J. Liu, J. Yin, O. F. Mohammed, O. M. Bakr, Y. Liu, B. Yang and H. Zhang, J. Am. Chem. Soc., 2017, 139, 4318.

21 T. Udayabhaskararao, Y. Sun, N. Goswami, S. K. Pal, K. Balasubramanian and T. Pradeep, Angew. Chem., Int. Ed., 2012, 51, 2155.

22 S. Wang, X. Meng, A. Das, T. Li, Y. Song, T. Cao, X. Zhu, M. Zhu and R. Jin, Angew. Chem., Int. Ed., 2014, 53, 2376.

23 Z. Lei, X.-L. Pei, Z.-J. Guan and Q.-M. Wang, Angew. Chem., Int. Ed., 2017, 56, 7117.

24 Z. Lei, X.-L. Pei, Z.-G. Jiang and Q.-M. Wang, Angew. Chem., Int. Ed., 2014, 53, 12771.

25 X. Kang, S. Wang, Y. Song, S. Jin, G. Sun, H. Yu and M. Zhu, Angew. Chem., Int. Ed., 2016, 55, 3611.

26 M. S. Bootharaju, C. P. Joshi, M. R. Parida, O. F. Mohammed and O. M. Bakr, Angew. Chem., Int. Ed., 2016, 55, 922.

27 L. G. AbdulHalim, M. S. Bootharaju, Q. Tang, S. D. Gobbo, R. G. AbdulHalim, M. Eddaoudi, D.-e. Jiang and O. M. Bakr, J. Am. Chem. Soc., 2015, 137, 11970.

28 G. Soldan, M. A. Aljuhani, M. S. Bootharaju, L. G. AbdulHalim, M. R. Parida, A.-H. Emwas, O. F. Mohammed and O. M. Bakr, Angew. Chem., Int. Ed., 2016, 55, 5749.
29 X. Kang, L. Xiong, S. Wang, H. Yu, S. Jin, Y. Song, T. Chen, L. Zheng, C. Pan, Y. Pei and M. Zhu, Chem.-Eur. J., 2016, 22, 17145.

30 Y. Wang, H. Su, L. Ren, S. Malola, S. Lin, B. K. Teo, H. Häkkinen and N. Zheng, Angew. Chem., Int. Ed., 2016, $55,15152$.

31 R.-W. Huang, Y.-S. Wei, X.-Y. Dong, X.-H. Wu, C.-X. Du, S.-Q. Zang and T. C. W. Mak, Nat. Chem., 2017, 9, 689.

32 F. Wang and X. Liu, Chem. Soc. Rev., 2009, 38, 976.

33 D. Wu, A. C. Sedgwick, T. Gunnlaugsson, E. U. Akkaya, J. Yoon and T. D. James, Chem. Soc. Rev., 2017, 46, 7105.

34 G. H. Carey, A. L. Abdelhady, Z. Ning, S. M. Thon, O. M. Bakr and E. H. Sargent, Chem. Rev., 2015, 115, 12732.

35 Z. Wu and R. Jin, Nano Lett., 2010, 10, 2568.

36 X. Kang, X. Li, H. Yu, Y. Lv, G. Sun, Y. Li, S. Wang and M. Zhu, RSC Adv., 2017, 7, 28606.

37 A. Kim, C. Zeng, M. Zhou and R. Jin, Part. Part. Syst. Charact., 2017, 34, 1600388.

38 X. Liu, J. Yuan, C. Yao, J. Chen, L. Li, X. Bao, J. Yang and Z. Wu, J. Phys. Chem. C, 2017, 121, 13848.

39 K. Zheng, X. Yuan, K. Kuah, Z. Luo, Q. Yao, Q. Zhang and J. Xie, Chem. Commun., 2015, 51, 15165.

40 X. Dou, X. Yuan, Y. Yu, Z. Luo, Q. Yao, D. T. Leong and J. Xie, Nanoscale, 2014, 6, 157.

41 (a) J. Mei, N. L. C. Leung, R. T. K. Kwok, J. W. Y. Lam and B. Z. Tang, Chem. Rev., 2015, 115, 11718; (b) R. Hu, N. L. C. Leung and B. Z. Tang, Chem. Soc. Rev., 2014, 43, 4494; (c) Y. Hong, J. W. Y. Lam and B. Z. Tang, Chem. Soc. Rev., 2011, 40, 5361; (d) J. Wu, W. Liu, J. Ge, H. Zhang and P. Wang, Chem. Soc. Rev., 2011, 40, 3483.

42 (a) Z. Ning, Z. Chen, Q. Zhang, Y. Yan, S. Qian, Y. Cao and H. Tian, Adv. Funct. Mater., 2007, 17, 3799; (b) D. Ding, K. Li, B. Liu and B. Z. Tang, Acc. Chem. Res., 2013, 46, 2441; (c) Y. Cui, B. Chen and G. Qian, Coord. Chem. Rev., 2014, 273, 76; (d) J. Mei, Y. Hong, J. W. Y. Lam, A. Qin, Y. Tang and B. Z. Tang, Adv. Mater., 2014, 26, 5429; (e) R. T. K. Kwok, C. W. T. Leung, J. W. Y. Lam and B. Z. Tang, Chem. Soc. Rev., 2015, 44, 4228.

43 X. Kang, M. Zhou, S. Wang, S. Jin, G. Sun, M. Zhu and R. Jin, Chem. Sci., 2017, 8, 2581.

44 M. S. Bootharaju, S. M. Kozlov, Z. Cao, M. Harb, M. R. Parida, M. N. Hedhili, O. F. Mohammed, O. M. Bakr, L. Cavallo and J.-M. Basset, Nanoscale, 2017, 9, 9529.

45 H. Wu, H. Zhu, J. Zhuang, S. Yang, C. Liu and Y. C. Cao, Angew. Chem., Int. Ed., 2008, 47, 3730.

46 (a) S. A. Macgregor and T. Wondimagegn, Organometallics, 2007, 26, 1143; (b) S. A. Macgregor and P. Vadivelu, Organometallics, 2007, 26, 3651; (c) D. Hill, C. Delaney, M. Clark, M. Eaton, B. Hassan, O. Hendricks, D. K. Dang and R. U. Kirss, $R S C A d v ., 2017,7,34425$. 